\title{
Effect of COVID-19 pandemic on anxiety and burnout levels in emergency healthcare workers: a questionnaire study
}

\section{Taner Sahin ( $\nabla$ drmtsahin@gmail.com )}

Kayseri City Hospital affiliated with University of Health Sciences Turkey https://orcid.org/0000-0002-77835343

\section{Humeyra Aslaner}

Kayseri City Hospital affiliated with University of Health Sciences Turkey

\section{Ozlem Olguner Eker}

Kayseri City Hospital affiliated with University of Health Sciences Turkey

\section{Mebrure Beyza Gokcek}

Health Directorate Kayseri

\section{Murat Dogan}

Kayseri City Hospital affiliated with University of Health Sciences Turkey

\section{Research article}

Keywords: COVID-19, Emergency Service, Healthcare Worker, Beck Anxiety Inventory, Maslach Burnout Inventory

Posted Date: June 4th, 2020

DOI: https://doi.org/10.21203/rs.3.rs-32073/v1

License: (9) (1) This work is licensed under a Creative Commons Attribution 4.0 International License. Read Full License

Version of Record: A version of this preprint was published on September 16th, 2020. See the published version at https://doi.org/10.18535/ijmsci/v7i09.010. 


\section{Abstract}

\section{Background}

During the COVID19 pandemic, an increase in anxiety and burnout levels may occur unwittingly due to the increased workload and intense stress experienced by emergency healthcare workers dealing with potential or suspected COVID-19 and other emergency patients. In our study, it is aimed to investigate whether there is an increase of anxiety and burnout levels of the healthcare workers working in ES and pandemic fields fighting against the outbreak of COVID-19 in Turkey, compared to other healthcare workers.

\section{Methods}

The study was carried out between April 1 to May 15,2020, with the online questionnaire method with the participation of 920 healthcare workers that are working actively in pandemic hospitals, emergency call ambulances, primary healthcare institutions and dental hospitals across the country. In the questionnaire, the sociodemographic characteristics of the participants were questioned, and Beck anxiety scale (BAI) and Maslach Burnout Inventory (MBI) were applied.

\section{Results}

The median age of the participants was 35.00 (minimum 20, maximum: 65 ), $59.2 \%$ were female and $40.8 \%$ were male. $22.3 \%$ of the personnel were working in the ES, $20.9 \%$ in the ambulance, $12.2 \%$ in the pandemic polyclinics. The pandemic area and the intensive care workers' BAI score are similar to those in the emergency service and ambulance $(p=0.05)$. The MBI-desensitization score of those working in the field of ED, ICUs and pandemics was higher than other places $(p<0.05)$. The MBI-emotional score of the emergency and ambulance workers was higher $(p=0.001)$, and the MBI-personal accomplishment score was lower than radiology, laboratory and office personnel $(\mathrm{p}=0.049)$.

\section{Conclusions}

The COVID-19 outbreak may create stress in healthcare workers, leading to various psychiatric disorders such as anxiety, depression, and burnout syndrome. Early recognition, prevention and coping methods of burnout and anxiety in healthcare workers play a key role in during the pandemic period.

\section{Introduction}

\section{Background}

Coronaviruses (CoV) is a large family of viruses that cause serious diseases such as common cold, Middle East Respiratory Syndrome Coronaviruses (MERS-CoV) and Severe Acute Respiratory Syndrome (SARS-CoV) $(1-4)$.

SARS-CoV emerged as a previously unknown virus in 2003 as the first international health emergency of the 21 st century, causing hundreds of people to die $(1,5)$. 
On December 31, 2019, Country Office of WHO for China reported pneumonia cases of unknown aetiology in Wuhan Hubei province, China. On January 7, 2020, the causative agent has been identified as a new coronavirus (2019-nCoV) that has not previously been detected in humans. Later, the name of 2019-nCoV disease was accepted as COVID-19(2,3,6).

\section{Importance}

After the first COVID-19 cases were seen in China, the disease spread rapidly in other countries and WHO declared the COVID-19 outbreak on March 11, 2020 as a pandemic (7). Panic and chaos began to occur around the world due to new cases and deaths, and serious measures had to be taken in healthcare systems. Hospitals had to accept a large number of new COVID-19 cases. Meanwhile, emergency services(ES) remained in the middle of the pandemic due to excessive patient entry. During the pandemic, ES were forced to look after both COVID-19 patients and other emergency patients, and even non-emergency polyclinic patients.

Anxiety is an intense emotion which is experienced in some periods of a person's life and which resembles fear. Anxiety not at the degree of a disease is the body's response to a stressor, helping the person survive by keeping him/her alert against danger. It may cause a very mild sense of anxiety or tension to intense emotion in the degree of panic. If it is experienced seriously, the person's self is crushed under this intense emotion and it becomes disturbing (8). Beck Anxiety Inventory (BAI) was developed by Beck, Epstein, Brown and Steer in 1988. BAl is an indicator has become a standard tool to measure anxiety level in researches. The scale aims to determine the frequency and severity of anxiety symptoms experienced by individuals (9). Burnout syndrome (BOS) was discovered in the early 1970s, especially among healthcare workers(HCW), those working in human services $(10,11)$. BOS is defined as the excessive use of energy and resources that cause emotional stress in the workplace or feelings of failure and exhaustion $(11,12)$. The clinical symptoms of BOS are not specific and include fatigue, headaches, eating problems, insomnia, irritability, emotional instability, and stiffness in relationships with other people. The best-studied BOS measurement in the literature is the Maslach Burnout Inventory (MBI). It was developed by Maslach and Jackson (13). MBI scale measures the effects of emotional exhaustion(EE), depersonalization (DP, negative or sarcastic attitudes towards patients) and reduced sense of personal accomplishment(PA). This indicator has become a standard tool to measure BOS in researches related to the syndrome. People who experience all three symptoms feel the BOS most, but emotional exhaustion has been identified as a hallmark of BOS $(11,14,15)$.

\section{Goal of This Investigation}

The main goal of this study is to determine whether there is an increase of anxiety and burnout levels of the HCWs working in ES and pandemic fields (PF) fighting against the early outbreak of COVID-19 in Turkey, compared to other HCWs.

\section{Methods}

\section{Study design and setting}


Our study was created with a web-based and multiple-choice questionnaire method. Healthcare staff working in places such as pandemic hospitals, primary healthcare centres, dental units throughout the country were contacted by phone, and the link of the questionnaire prepared in Turkish was sent by text message or e-mail and their consents were requested. BAI was used to determine the level of anxiety, and MBI was used to determine the level of burnout, and participants were asked to fill these scales as multiple choice. These scales are in the form of multiple-choice options, and score according to the peer equivalents of each option. Statistical analysis of the data obtained have been performed by a computer.

\section{Selection of Participants}

The consents of the participants were asked in the questionnaire form and the people giving consent were included in the study.

930 people participated in the study including doctors, nurses, emergency medical technician(EMT) or paramedics, laboratory staff working actively in places such as ES, PF policlinics, intensive care units (ICU), laboratory, radiology and office workers of pandemic hospitals, and also dental unit staff, ambulance staff, patient transport staff, security staff, cleaning, office and administrative staff between the ages of 20 and 65 , 10 people who did not give consent have been excluded from the study and as a result, 920 people who gave consent filled the online questionnaire between April 1 to May 1, 2020.

\section{Measurements}

In our study, besides these two scales, basic epidemiological information was questioned. In the first part of the questionnaire, the sociodemographic characteristics of the participants were questioned, and in the second part, BAI and MBI, which will determine the level of anxiety and burnout of the participants, were applied.

\section{Outcomes}

$\mathrm{MBI}$ was used to determine the level of anxiety and BAI to determine the level of BOS. These scales are in the form of multiple-choice options, and they score according to the peer equivalents of each option.

The BAl scale consists of 21 questions in the 4 Likert type (0: None, 1: Mild level - did not affect me very much, 2: Moderate level - It was not pleasant but I could endure, 3: Serious level - I had a hard time withstanding). According to the BAI, people receive minimum: 0 points, maximum: 63 points. BAI scores between 8-15 points considered as people with mild anxiety level, 16-25 points moderate anxiety level and 25-63 points an increased anxiety level.

The MBI scale consists of 5 questions in the Likert type (0: Never, 1: Very rare, 2: Sometimes, 3: Most of the time, 4: Always). It has three dimensions such that EE nine items, DP five items and PA eight items. MBI is scaled by classifying according to EE (minimum: 0 points, maximum: 45 points), DP (minimum: 0 points, maximum: 25 points) and PA (minimum: 0 points, maximum: 40 points).

\section{Ethics approval}


Ethics approval was obtained through the Turkish Ministry of Health Scientific Research Platform with May 1, 2020 date and the ethics board of the Kayseri City Hospital April 30, 2020 date and with 30 number. The study adhered to Declaration of Helsinki (16).

\section{Data Analysis}

\section{Data screening process}

Power analysis has been performed using $\mathrm{G}^{*}$ power 3.1 analysis program to determine the sample size. The minimum number of people to participate in the study has been determined as 624 (a- value:0.05, ßvalue:0.80).

\section{Statistical analysis}

The data obtained as a result of our research was processed on the computer using IBM SPSS Statistics for Windows, version 21 package program. In the analysis of the data, frequency, mean, median and standard deviation, minimum and maximum values were determined as descriptive data. Chi-square test was used to compare categorical data. In the numerical data, Student's t-test was applied in binary groups that conformed to the normal distribution, and the Mann Whitney $U$ test was used in the groups that did not conform to the normal distribution. One Way Anowa test was used to compare more than two groups that conform to normal distribution and Kruskal Wallis test was used to compare more than two groups that did not conform to normal distribution. Post-Hoc Tukey correction and Dunn correction was made. Spearman correlation analysis was used to evaluate the relationship among numerical data and the significance level was set at a p-value of 0.05 .

\section{Results}

\section{Subject Characteristics}

A total of $545(59.2 \%)$ of the 920 participants were female and 375 (40.8\%) were male. The median age of the participants was 35.00 (youngest: 20, oldest: 65$)$. A total of $249(27.1 \%)$ of them were single or divorced and; 671 (72.9\%) were married. Of the participants 205 (22.3\%) were working in ES,192 (20.9\%) in the ambulance, $112(12.2 \%)$ in pandemic polyclinics and ICU, and 411 (44\%) 6) in other hospital areas such as other polyclinics, patient services (PS), public health $(\mathrm{PH})$, family medicine (FP), laboratory, radiology unit, office and dental units. Of the participants 249 (27.1\%) were doctors, 301 (32.79\%) were health officials and nurses, 180 (19.6) were paramedics and/or EMT, 190 (20.7\%) were radiology, laboratory, office and other hospital area staff. The average term of office of the participants were 12,00(minimum: 1, maximum: 35) years. 390 $(42.4 \%)$ of the participants were working daytime shift, while 530 (57.6\%) were working 24-hour shift (Table 1).

Of the participants, 226 (24.6\%) of them were living with their family members over the age of 65 or with a chronic disease. 596 (64.8\%) of them had children(Table 1).

Table 1. Distribution of participants by age, gender, marital status, workplace, profession, term of office and work shift 
Of the participants, 743 (80.8\%) of them thought the COVID-19 outbreak had affected their mental health and, $472(51.3 \%)$ of them were serving COVID-19 patients with possible or definitive diagnosis and, $654(71.1 \%)$ of them were thinking that they had adequate personal protective equipment (PPE) or disinfectant at the place where they were working, but $729(79.2 \%)$ of them were thinking that PPE was not adequately protecting themselves. Of the participants, 801 (87.1\%) was afraid being infected with COVID-19 and therefore was washing their hands on average 15.00 (minimum:2, maximum:95) times a day (Table 2).

Table 2. Participants' feelings about COVID-19, distribution by PPE protection and handwashing status questions.

\section{The BAI and MBI score analysis of all participants and their median scores by the study field and professions}

The mean BAI score of the HCWs was 14 (minimum:0, maximum: 63). The mean of the HCWs MBI-EE score was 10 (minimum:9, maximum: 45), the mean of MBI-DP score was 5.8 (minimum:5, maximum: 5-25) and, the mean of MBI-PA score was 6.7 (minimum:8-maximum:40), (Table 3).

\section{The BAI scores analysis of the participants by the study field}

There was no statistically significant difference between the groups when the BAI score was analyzed according to the study fields ( $\mathrm{p}$ : 0.005). Kruskal Wallis test was applied ( Table 3).

The BAI score of the PF and ICU workers was similar to ES and ambulance workers and there was no statistically significant difference between them ( $p$ : 0.053) (Table 3).

The BAI score of PF and ICU workers was significantly higher than that of PH, FP, service and other policlinic workers, and there was a statistically significant difference (p: 0.046 ). The BAI score of PF and ICU workers was significantly higher than that of radiology, laboratory and office workers, and there was a statistically significant difference (p:0.004), (Table 3).

\section{The MBI scores analysis of the participants by the study field}

There was a statistically significant difference between the groups the MBI scores were observed by study fields (p: 0.001). Kruskal Wallis test and Dunn's correction was applied (Table 3,4).

\section{The MBI-EE scores analysis of the participants by the study fieldand profession}

The ES and ambulance workers had a statistically significant difference in MBI-EE score compared to the radiology, laboratory and office workers. The MBI-EE score of the ES and ambulance workers was higher than the others (p:0.001),(Table 4).

The PF and ICU workers had a statistically significant difference in MBI-EE score compared to radiology, laboratory and office workers. The MBI-EE scores of PF and ICU workers were higher than the others (p: 0.000), (Table 4).

The $\mathrm{PH}, \mathrm{FP}$, other policlinic and service workers had a statistically significant difference in MBI-EE score compared to the radiology, laboratory and office workers. The MBI-EE scores of the PH, FP, other policlinic and 
service workers were higher than the others (p:0.006), (Table 3,4).

\section{The MBI-DP scores analysis of the participants by the study field and profession}

There was a statistically significant difference between the groups the MBI-DP scores were observed by study areas (p: 0.015). Kruskal Wallis test and Dunn's correction was applied (Table 3,4).

The ES and ambulance workers had a statistically significant difference in MBI-DP score compared to the radiology, laboratory and office workers. The MBI-DP score of ES workers was higher than the others (p: 0.003), (Table 3,4).

The PF and ICU workers had a statistically significant difference in MBI-DP score compared to the radiology, laboratory and office workers. The MBI-DP score of PF and ICU workers was higher than the others (p:0.026), (Table 3,4).

\section{The MBI-DP scores analysis of the participants by the study field and profession}

There was a statistically significant difference between the groups the MBI-DP scores were observed by study areas (p: $\mathbf{0 . 0 0 0 )}$. Kruskal Wallis test was and Dunn's correction was applied (Table 3,4).

The ES and ambulance workers had a statistically significant difference in MBI-DP score compared to the radiology, laboratory and office workers. The MBI-PA score of ES and ambulance workers was lower than the others (p: 0.049), (Table 3,4)

The PF and ICU workers had a statistically significant difference in MBI-DP score compared to ES and ambulance workers. The MBI-PA score of PF and ICU was lower than the ES and ambulance workers (p: 0.027),(Table 3,4).

The PF and ICU workers had a statistically significant difference in MBI-DP score compared to radiology,

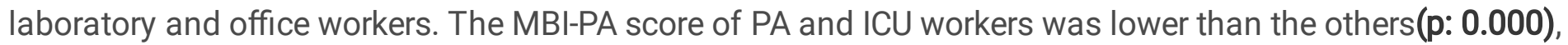
(Table 3,4).

The PF and ICU workers had a statistically significant difference in MBI-DP score compared to radiology, laboratory and office workers. The MBI-PA score of PA and ICU workers was lower than the others (p:0.023), (Table 3,4).

\section{The BAI and MBI score analysis of all participants and their median scores by profession}

The groups were classified and analyzed according to the professions of the participants (Table 3).

\section{The BAl score analysis of all participants and their median scores by profession}

There was no statistically significant difference between the groups BAI score by profession was observed (p: 0.154). Kruskal Wallis Test was applied. (Table 3).

\section{The MBI score analysis of all participants and their median scores by profession}


There was a statistically significant difference among groups when looking at MBI-EE score by profession (p: 0.000). Kruskal Wallis Test was applied. Accordingly, the MBI-EE score of the doctors was significantly higher than that of the nurse and health officers (p: 0.003$)$, paramedic, EMT and other staff (p: $\mathbf{0 . 0 0 0 )}$, (Table 3,4).

\section{The MBI-DP score analysis of all participants and their median scores by profession}

There was a statistically significant difference among groups when MBI-DP score was observed by profession (p: 0.000). Kruskal Wallis Test was applied. Accordingly, the MBI-DP score of the doctors was significantly higher than that of the nurses, officers, paramedics, EMTs and other staff (p: 0.000), (Table 3,4).

\section{The MBI-PA score analysis of all participants and their median scores by profession}

There was a statistically significant difference among groups when MBI-PA score by profession was observed (p: 0.000). Kruskal Wallis Test was applied (Table 3,4). Accordingly, the MBI-PA score of the doctors was significantly lower than that of the paramedic and EMT group (p: 0.000 ). The MBI-PA score of the doctors was significantly lower than that of the nurses ( $\mathbf{p :} \mathbf{0 . 0 2 8}$ ) and the MBI-PA score of the doctors was lower than that of the other staff, but there was no statistically significant difference (p:0.499), (Table 3,4).

Table 3. The median BAI and MBI scores of all participants and their median scores by field of study and profession

Table 4. The MBI-EE, DP and PA scores comparison by study areas

\section{The BAI and MBI scores analysis of the participants by the survey questions}

\section{The BAl score analysis of the participants by the survey questions}

The HCWs who lived with their relatives over 65 years and females the BAI scores were significantly higher than others (all p: 0.000), (Table 5).

The BAl score of the HCWs who thought that they were mentally affected by COVID-19 outbreak, serving for the patient with suspected COVID-19, those who were thinking that there was enough PPE but, that PPE did not protect themselves sufficiently and were afraid of infected with COVID-19 was significantly higher than the others(all p:0.000), (Table 5).

\section{The $\mathrm{MBI}$ score analysis of the participants by the survey questions}

\section{The MBI-EE score analysis of the participants by the survey questions}

Female and singles HCWs' MBI-EE scores was significantly higher than others(p: $\mathbf{0 . 0 0 0 )}$. The HCWs who lived with over 65 years old relative or had a relative with a chronic disease had significantly higher MBI-EE scores than others (p: 0.007). Also, the HCWs who lived with their children had significantly higher MBI-EE scores than the others (p: 0.005), (Table 5). 
The MBI-EE score of the HCWs who thought that they were mentally affected by COVID-19 outbreak, serving for the patient with suspected COVID-19, those who were thinking that there was enough PPE but, that PPE did not protect themselves sufficiently and were afraid of infected with COVID-19 was significantly higher than the others (all p:0.000), (Table 5).

\section{The MBI-DP score analysis of the participants by the survey questions}

The HCWs who thought that they were mentally affected by COVID-19 outbreak had significantly higher MBIDP scores than others(p: 0.04). The HCWs who lived with their children had significantly higher MBI-DP scores than others (p: 0.003). The MBI-DP score of the HCWs who serving for the patient with suspected COVID-19, and who were thinking that PPEs were not adequately protected was significantly higher than the others (all p: 0.000). The HCWs who were thinking that there was enough PPE had significantly higher MBI-DP score than the others. (p:0.004), (Table 5).

\section{The MBI-PA score analysis of the participants by the survey questions}

The HCW providing care for patients with suspected COVID-19 had significantly lower MBI-PA score than others(p: 0.02). The HCWs who were thinking that there was enough PPE had significantly higher MBI-PA score than others (p: 0.035) (Table 5).

Table 5. Comparison of Beck Anxiety Inventory and Maslach Burnout Inventory scores according to the survey questions

\section{Spearman Correlation analysis}

Correlation analysis was performed among BAI and $\mathrm{MBI}$ subgroups of the participants. Accordingly, the HCWs had a weakly significant correlation between the BAI score and the MBI-DP score (p: 0.000, r: 0.470); also, they had a weakly positive and significant relationship between the BAI score and the MBI-DP score (p: $0.000, \mathbf{r}$ : 0.240).(Table 6).

While, there was a weakly negative and significant relationship between the BAI score and the MBI-DP score of the HCWs (p: $\mathbf{0 . 0 0 0 , r : - 0 . 1 6 2 ) . ~ T h e r e ~ w a s ~ a ~ p o s i t i v e ~ a n d ~ h i g h l y ~ s i g n i f i c a n t ~ r e l a t i o n s h i p ~ b e t w e e n ~ B A I ~ s c o r e ~}$ and the MBI-DP score of the HCWs (p: 0.000, r: 0.693).(Table 6).

Finally, there was a negative and weakly significant relationship between the MBI-EE score and the MBI-PA score of HCWs (p: $\mathbf{0 . 0 0 0}, \mathbf{r}:-\mathbf{0 . 3 0 6})$. There was a negative and weakly significant relationship between the MBIDP score and the MBI-PA score of HCWs (p:0.000, r:-0.335). (Table 6).

Table 6. Spearman Correlation analysis of BAI and MBI scores.

\section{Discussion}

The COVID-19 pandemic causes stress and tension in all people around the world, increases future related anxiety due to changing conditions, and brings together findings of many psychiatric disorders such as anxiety, BOS and depression (17). The HCWs who are working in COVID-19 pandemic fields, especially in EPs, 
are at the forefront of fighting against this pandemic disease in our country as in the whole world. For this reason, ES workers are faced with a more intensive working tempo during the pandemic period in Turkey as well as all over the world. Therefore, anxiety level increase or BOS symptoms may occur in all the HCWs who working in the field of pandemics, especially ES. In general, the HCWs are not aware of these situations. In our study we found, when HCWs were evaluated in terms of professional groups, there was no difference in terms of their anxiety levels, while MBI-EE and MBI-DP scores of ES and ambulance workers were significantly higher and their MBI-PA scores were lower than other HCWs. Besides, MBI-EE and DP scores were significantly higher in pandemic polyclinics and ICU workers compared to other HCWs, while MBI-PA scores were similarly lower. The HCWs who worked in PF policlinics and ICU had higher BAI scores than PH, FP, PS, other policlinics, radiology, laboratory and office workers. The findings are similar to the literature. In studies conducted, higher levels of burnout of HCWs providing emergency health services were specified $(10,18,27,19-26)$. Also, especially in ES and other HCWs, the intensive workload, the necessity of continuing work life during the pandemic increases the stress and burnout related to the risks taken during the care and treatment processes of COVID-19 patients. ES workers experienced this workload and intense stress in the H1N1 influenza pandemic in 2009 and locally in the SARS pandemic in 2003 and MERS in 2012 and remained amid the pandemic. $(1,19)$.

These results of the BAI and $\mathrm{MBI}$ scores in our study are compatible with low levels of anxiety and burnout in HCWs, and lower than some studies in the literature $(10,28,29)$ and, are similar to some studies $(19,30-32)$. In our study, working in ES was found to be a factor increasing MBI-EE and DP scores, while decreasing MBI-PA scores. BOS can be considered as a marker of the health of the healthcare team. ICU workers, like ES workers, are under heavy workload and stress. Takayesu JK et al. in their study specified that $65 \%$ of ES workers had BOS symptoms (33). In the literature study of investigating the BOS level, they stated that even if there was no pandemic, the number of people who showed BOS symptoms in ES workers was up to $60 \%$ levels (10). In another study, the levels of MBI-EE, DP, PA, anxiety, and depression of ES workers exposed to violence while working were shown to be associated with violence exposure (27). We thought that the reasons for intense stress, increase in BAI and $\mathrm{MBI}$ levels of ES workers are working with intense tempo, having to look at other emergency cases besides suspect cases of COVID-19, long shift hours, job dissatisfaction and not being appreciated by hospital administrations.

In our study, the BAI score and MBI-EE and DP scores of women and HCW those who lived with their relatives over 65 years of age were higher, while MBI-PA scores were significantly lower. In the literature, anxiety and burnout levels were generally reported higher in women $\mathrm{HCWs}$, and the findings were consistent with the literature $(34,35)$. Besides, in a comprehensive study conducted in China due to the COVID-19 outbreak, anxiety levels were found higher in women HCWs (17). Another study about the effects of COVID-19 pandemic in 2020 on the mental health of HCWs, reported that higher levels of stress, anxiety, and depression symptoms in women, those with suspected COVID-19 family members (36). In literature studies, while SARS outbreak has been stated that the causes of anxiety during the SARS outbreak were familial causes such as anxiety to infect children or family members of children or family members. $(21,22,37)$. The MBI-EE and DP scores of the HCWs who had children included in our study were significantly higher. The fact that MBI-EE is less common among those who have children is a finding highlighted in previous studies $(38,39)$. In our study, we thought that HCWs, who have children at home, who live with a family member over 65 years old and/or 
who have a chronic illness living in their homes, maybe a reason that increases the level of fear, anxiety and burnout of these people.

Also in our study, while the MBI-EE and DP scores of the doctors were higher than the other staff, the MBI-PA scores were low. Again, MBI-EE and DP scores of doctors and nurses were found to be higher than other HCWs and MBI-PA scores were similarly lower. In the literature, it is stated that nurses and physicians are the most risky group among HCW in terms of burnout $(31,40)$. In a study, it was determined that doctors had higher MBI-EE scores than other HCWs and doctors had lower MBI-PA scores. (31). We thought that this finding, which was supported in our study, maybe due to active workloads in the diagnosis and treatment processes of doctors and nurses during the COVID-19 pandemic period and their close contact with COVID-19 patients. Unlike studies conducted during SARS, H1N1 and COVID-19 pandemic studies $(32,36,37)$ in our study, we thought that the reason of anxiety levels of doctors being higher than anxiety levels of other HCWs might be that doctors had to take nose, throat swabs from patients, and had closer contact with the patient while examining and they were afraid of getting infected. Considering the literature studies on the BOS level of ES workers who are constantly facing pandemic and infectious diseases, BOS levels of ES workers are generally calculated to be higher. Qiao Z et al. in their study, stated that HCWs serving people with HIV/AIDS had significantly higher MBI-EE and DP scores than other HCWs (40). In our study, the BAI score of the HCWs who were providing care for the patient with suspected COVID-19 were significantly higher. While MBI-EE and DP scores were significantly higher, MBI-PA scores were also significantly lower. In a study reported recently from Hubei province of China, average anxiety scores were found to be significantly higher in HCW who directly treated confirmed cases of COVID-19 than those who treated the patients that were not diagnosed with COVID-19 (41). In the light of this information, it can be said that HCWs who directly treat cases with confirmed COVID-19 during the COVID-19 outbreak are mentally at more risk.

In our study, although 71.1 per cent of the respondents thought that there was sufficient personal protective equipment (PPE), the rate of those who thought that PPE did not protect itself sufficiently is 79.2 per cent. Zhu Z. et. al. in a study they conducted on COVID-19, stated that 83.6 per cent of the participants were satisfied with the support provided by the hospital management and PPE status (36). Interestingly, HCWs who thought that there was enough PPE in our study are found to have a significantly higher the BAl score as well as the MBI-EE and DP scores. This may be because most of the participants ( 80.8 per cent) thought that the COVID19 outbreak affected them spiritually.

\section{Limitations}

In addition to determining the anxiety and burnout levels of ES and ICU workers, we thought that nonevaluation of depression levels and quality of life is the deficiency of our study. Also, it is a limitation that the evaluations are not supported by clinical examinations. In subsequent studies, clinical psychiatric examinations of the participants can be performed and comparisons can be made with BAI and MBI scores.

\section{Conclusions}

Mental health of HCWs also affects the quality of healthcare service they provide. For this reason, we think that it is important to identify and prevent burnout and anxiety early in HCWs, identify effective methods for 
coping and increase their quality of life.

As a result, we found that ES workers' anxiety levels were similar to those of ICU and pandemic region, and that ES workers had higher MBI-EE and DP and lower MBI-PA scores than other HCWs. We recommend that inservice training and psychosocial support should be provided by hospital administrations to HCWs, especially those working in ES, ICU, and pandemic services of pandemic hospitals and pandemic fields.

\section{Abbreviations}

CoV: Coronaviruses

MERS-CoV: Middle East Respiratory Syndrome Coronaviruses

SARS-CoV: Severe Acute Respiratory Syndrome

ES: Emergency Services

BOS: Burnout Syndrome

HCW: Health Care Workers

BAl: Beck Anxiety Inventory

MBI: Maslach Burnout Inventory

EE: Emotional Exhaustion

DP: Depersonalization

PA: Personal Accomplishment

PF: Pandemic Field

ICU: Intensive Care Unit

PS: Pandemic Service

FP: Family Practitioner

PH: Public Health

EMT: Emergency Medicine Technician

PPE: Personal Protective Equipment

WHO: World Health Organization

\section{References}


1. de Wit E, van Doremalen N, Falzarano D, Munster VJ. SARS and MERS: recent insights into emerging coronaviruses. Nat Rev Microbiol. 2016;14(8):523.

2. Organization WH. Surveillance case definitions for human infection with novel coronavirus ( $\mathrm{nCoV}$ ): interim guidance v1, January 2020. World Health Organization; 2020.

3. Organization WH. Infection prevention and control during health care when novel coronavirus (nCoV) infection is suspected Interim guidance, 19 March 2020. 2020;

4. Huang C, Wang Y, Li X, Ren L, Zhao J, Hu Y, et al. Clinical features of patients infected with 2019 novel coronavirus in Wuhan, China. Lancet. 2020;395(10223):497-506.

5. Turkey Ministry Of Health. COVID-19 Rehberi. COVID-19 Rehb [Internet]. 2020;19. Available from: https://covid19bilgi.saglik.gov.tr/depo/rehberler/COVID-19_Rehberi.pdf. Accessed 13 April 2020.

6. Organization WH. Laboratory testing for coronavirus disease 2019 (COVID-19) in suspected human cases: interim guidance, 2 March 2020. World Health Organization; 2020.

7. Organization WH. WHO Director-General's opening remarks at the media briefing on COVID-19 - 11 March 2020 [Internet]. [cited 2020 May 4]. Available from: https://www.who.int/dg/speeches/detail/whodirector-general-s-opening-remarks-at-the-media-briefing-on-covid-19--11-march-2020. Accessed 18 March 2020.

8. Silverman WK. Anxiety disorders interview schedule for DSM-IV.: parent interview schedule. Vol. 1. Oxford University Press; 1996.

9. Beck AT, Epstein N, Brown G, Steer RA. An inventory for measuring clinical anxiety: psychometric properties. J Consult Clin Psychol. 1988;56(6):893.

10. Goldberg R, Boss RW, Chan L, Goldberg J, Mallon WK, Moradzadeh D, et al. Burnout and its correlates in emergency physicians: four years' experience with a wellness booth. Acad Emerg Med. 1996;3(12):115664.

11. Maslach C, Schaufeli WB, Leiter MP. Job burnout. Annu Rev Psychol. 2001;52(1):397-422.

12. Pines A, Maslach C. Characteristics of staff burnout in mental health settings. Psychiatr Serv. 1978;29(4):233-7.

13. Maslach C, Jackson SE. The measurement of experienced burnout. J Occup Behav 2: 99-113. 1981.

14. Maslach C, Jackson SE, Leiter MP, Schaufeli WB, Schwab RL. Maslach burnout inventory. Vol. 21. Consulting psychologists press Palo Alto, CA; 1986.

15. Maslach C, Jackson SE. Leiter MP Maslach burnout inventory manual. Palo Alto Calif Consult Psychol Press Inc. 1996;

16. Williams JR. The Declaration of Helsinki and public health. Bull World Health Organ. 2008;86:650-2.

17. Huang Y, Zhao N. Generalized anxiety disorder, depressive symptoms and sleep quality during COVID-19 outbreak in China: a web-based cross-sectional survey. Psychiatry Res. 2020;112954.

18. Tabolli S, lanni A, Renzi C, Di C Pietro, Puddu P. Job satisfaction, burnout and stress amongst nursing staff: a survey in two hospitals in Rome. G Ital Med Lav Ergon. 2006;28(1 Suppl 1):49-52.

19. Sünter AT, Canbaz S, Dabak Ş, Öz H, Pekşen Y. Pratisyen hekimlerde tükenmişlik, işe bağlı gerginlik ve iş doyumu düzeyleri. Genel Tıp Derg. 2006;16(1):9-14. 
20. Chong M-Y, Wang W-C, Hsieh W-C, Lee C-Y, Chiu N-M, Yeh W-C, et al. Psychological impact of severe acute respiratory syndrome on health workers in a tertiary hospital. Br J Psychiatry. 2004;185(2):127-33.

21. Maunder RG, Lancee WJ, Balderson KE, Bennett JP, Borgundvaag B, Evans S, et al. Long-term psychological and occupational effects of providing hospital healthcare during SARS outbreak. Emerg Infect Dis. 2006;12(12):1924.

22. Beauregard N, Marchand A, Blanc M-E. What do we know about the non-work determinants of workers' mental health? A systematic review of longitudinal studies. BMC Public Health. 2011;11(1):439.

23. Brady M. Death anxiety among emergency care workers. Emerg nurse. 2015;23(4).

24. Cook EJ. Pediatric Nurses' Death Anxiety and Level of Comfort in Approaching Families of Dying Children. 2011;

25. Brady M. Mortality face to face: Death anxiety in paramedics. J Paramed Pract. 2013;5(3):130-1.

26. Lehto R, Stein K. Death anxiety: an analysis of an evolving concept. 2009;

27. Roldán GM, Salazar IC, Garrido L, Ramos JM. Violence at work and its relationship with burnout, depression and anxiety in healthcare professionals of the emergency services. Health (Irvine Calif). 2013;5(02):193.

28. Martin F, Poyen D, Bouderlique E, Gouvernet J, Rivet B, Disdier P, et al. Depression and burnout in hospital health care professionals. Int J Occup Environ Health. 1997;3(3):204-9.

29. Zhang SX, Huang H, Wei F. Geographical distance to the epicenter of Covid-19 predicts the burnout of the working population: Ripple effect or typhoon eye effect? Psychiatry Res. 2020;112998.

30. Özkan Ş. Rol çatışması ve rol belirsizliğinin hekim ve hemşirelerin tükenmişlik düzeyleri üzerine olan etkileri. Hacettepe Üniversitesi, Ankara. 2008;77-87.

31. Doğan K, İlham MN, Aygün R. Üçüncü basamak çalışanlarında tükenmişlik: etkili kişisel ve mesleksel etmenler. Dahili Tıp Bilim Derg. 2006;1(3-4):178-84.

32. Goulia P, Mantas C, Dimitroula D, Mantis D, Hyphantis T. General hospital staff worries, perceived sufficiency of information and associated psychological distress during the A/H1N1 influenza pandemic. BMC Infect Dis. 2010;10(1):322.

33. Kimo Takayesu J, Ramoska EA, Clark TR, Hansoti B, Dougherty J, Freeman W, et al. Factors associated with burnout during emergency medicine residency. Acad Emerg Med. 2014;21(9):1031-5.

34. Vanagas G, Bihari-Axelsson S. The factors associated to psychosocial stress among general practitioners in Lithuania. Cross-sectional study. BMC Health Serv Res. 2005;5(1):45.

35. McMurray JE, Linzer M, Konrad TR, Douglas J, Shugerman R, Nelson K, et al. The work lives of women physicians. J Gen Intern Med. 2000;15(6):372-80.

36. Zhu Z, Xu S, Wang H, Liu Z, Wu J, Li G, et al. COVID-19 in Wuhan: Immediate Psychological Impact on 5062 Health Workers. medRxiv. 2020;

37. Tam CWC, Pang EPF, Lam LCW, Chiu HFK. Severe acute respiratory syndrome (SARS) in Hong Kong in 2003: stress and psychological impact among frontline healthcare workers. Psychol Med. 2004;34(7):1197-204.

38. Sahin D, Turan FN, Alparslan N, Sahin I, Faikoglu R, Gorgulu A. Burnout levels of health staff working in a state hospital/Devlet hastanesinde calisan saglik personelinin tukenmislik duzeyleri. Arch

Page $14 / 22$ 
Neuropsychiatry. 2008;45(4):116-22.

39. Baier N, Roth K, Felgner S, Henschke C. Burnout and safety outcomes-a cross-sectional nationwide survey of EMS-workers in Germany. BMC Emerg Med. 2018;18(1):24.

40. Qiao Z, Chen L, Chen M, Guan X, Wang L, Jiao Y, et al. Prevalence and factors associated with occupational burnout among HIV/AIDS healthcare workers in China: a cross-sectional study. BMC Public Health. 2016;16(1):335.

41. Liu C-Y, Yang Y, Zhang X-M, Xu X, Dou Q-L, Zhang W-W. The prevalence and influencing factors for anxiety in medical workers fighting COVID-19 in China: A cross-sectional survey. Available SSRN 3548781. 2020;

\section{Tables}

Table 1. Distribution of participants by age, gender, marital status, workplace, profession, term of office and work shift 
Gender $n(\%)$

Female

$545(59,2)$

Male

$375(40,8)$

Marital status $n(\%)$

Alone or divorced

$249(27,1)$

Married

$671(72,9)$

Workplace $n(\%)$

Emergency Service

$205(22,3)$

Ambulance

$192(20,9)$

Pandemic Policlinic and ICU

$112(12,2)$

Other Policlinic

$112(12,2)$

Patient Service

$77(8,4)$

Public health and Family Practise

102(11)

Laboratory, Radiology Unit and

120(13)

Office

Profession $n$ (\%)

Doctor

$249(27,1)$

Nurse

$301(32,79)$

Radiologist, Laboratory and other

$190(20,7)$

Paramedic/EM technician

$180(19,6)$

Term of office(year)

Work shift $n(\%)$

Day

24 hour

Live with $n(\%)$

Live with an over 65 years old family member and/or has chronic disease any family person $n(\%)$ 
No

Live with a child $\mathrm{n}(\%)$

Yes

$596(64,8)$

No

$324(35,2)$

Descriptive statistics are given as number (\%) for categorical variables and mean for numerical variables.

Table 2. Participants' feelings about COVID-19, distribution by PPE protection and handwashing status questions. 
Do you think that current events about COVID-19 affect your mental health? $n(\%)$

Yes

743

$(80,8)$

No

Undecided

Do you provide service to a patient with suspected / definitive COVID-19?n (\%)

Yes

No

Do you think there is enough personal protective equipment (mask, apron, glasses) and disinfectant in the hospital / where you work? $n$ (\%)

Yes

No

Do you believe that personnel protective equipment protect you? $n(\%)$

Yes

No

Are you afraid of getting COVID-19 infection? $n$ (\%)

Yes

No

How many times have you washed your hands / used disinfectants lately?

Mean $\pm S S(\min -\max )$

Descriptive statistics are given as number (\%) for categorical variables.

Table 3. The median BAI and MBI scores of all participants and their median scores by field of study and profession 


\begin{tabular}{|c|c|c|c|c|c|}
\hline & \multirow{3}{*}{$\begin{array}{l}\text { Count } n \\
(\%)\end{array}$} & \multirow{3}{*}{$\begin{array}{l}\text { BAl score } \\
\text { Median(min- } \\
\text { max) }\end{array}$} & \multirow{2}{*}{\multicolumn{2}{|c|}{$\begin{array}{l}\text { MBI score } \\
\text { Median(min-max) }\end{array}$}} & \multirow[b]{3}{*}{$\begin{array}{l}\text { Personal } \\
\text { accomplishment }\end{array}$} \\
\hline & & & & & \\
\hline & & & $\begin{array}{l}\text { Emotional } \\
\text { exhaustion }\end{array}$ & Depersonalization & \\
\hline $\begin{array}{l}\text { Median of all } \\
\text { participants }\end{array}$ & 920 & $14(0-63)$ & 10(9-45) & $5.8(5-25)$ & $6.7(8-40)$ \\
\hline \multicolumn{6}{|l|}{ Study field } \\
\hline $\begin{array}{l}\text { Emergency and } \\
\text { ambulance }\end{array}$ & 397 & $13(0-63)$ & $28(9-45)$ & $11(5-25)$ & $26(8-40)$ \\
\hline $\begin{array}{l}\text { Emergency } \\
\text { service }\end{array}$ & 205 & $13(0-55)$ & $31(10-45)$ & $13(5-25)$ & $25(10-39)$ \\
\hline $\mathrm{PH}, \mathrm{FP}, \mathrm{OP}$ and PS & 291 & $\begin{array}{l}16(0- \\
47)\end{array}$ & $28(9-45)$ & $11(5-25)$ & $27(8-40)$ \\
\hline $\begin{array}{l}\text { Laboratory, Radiology } \\
\text { Unit and } \\
\text { Office }\end{array}$ & 120 & $\begin{array}{l}11,5(0- \\
54)\end{array}$ & $23,5(9-45)$ & $9(5-25)$ & $29(9-40)$ \\
\hline $\begin{array}{l}\text { Pandemic Policinic } \\
\text { and ICU }\end{array}$ & 112 & $\begin{array}{l}18(4- \\
61)\end{array}$ & $30(9-45)$ & $12(5-25)$ & $25(9-40)$ \\
\hline Total & 920 & & & & \\
\hline \multicolumn{6}{|l|}{ Profession } \\
\hline Doctor & 249 & $15(0-59)$ & $25(8-39)$ & $31(11-45)$ & $13(5-25)$ \\
\hline Nurse & 301 & $\begin{array}{l}17(0- \\
63)\end{array}$ & $27(8-40)$ & $27(9-45)$ & $10(5-25)$ \\
\hline Paramedic or EMT & 180 & $\begin{array}{l}13,5(0- \\
58)\end{array}$ & $28(10-40)$ & $26(9-45)$ & $10(5-25)$ \\
\hline Other & 190 & $\begin{array}{l}11(0- \\
61)\end{array}$ & $26(9-40)$ & $25,5(9-45)$ & $10(5-25)$ \\
\hline Total & 920 & & & & \\
\hline
\end{tabular}

Descriptive statistics are given as number (\%) for categorical variables and median(minimum-maximum value) for numerical variables.

BAl: Beck Anxiety Inventory, MBI: Maslach Burnout Inventory, PH: Public Health, FP: Family Practise, OP: Other Policlinics, PS: Patient Service, EMT: Emergency Medicine Technician

Table 4. The MBI-EE, DP and PA scores comparison by study areas 


\begin{tabular}{|lcc|}
\hline MBI-EE score & & \\
\hline Study area & Compare to & p-value \\
\hline Emergency and ambulance & Laboratory, Radiology Unit and Office & 0,001 \\
\hline Pandemic Policinic and ICU & Laboratory, Radiology Unit and Office & 0,000 \\
\hline PH, FP, OP and PS* & Laboratory, Radiology Unit and Office & 0,006 \\
\hline MBI-DP score & & $p$ \\
\hline Study area & \multicolumn{1}{c}{ Compare to } & 0,003 \\
\hline Emergency and ambulance & Laboratory, Radiology Unit and Office \\
\hline Pandemic Policinic and ICU & Laboratory, Radiology Unit and Office & 0,026 \\
\hline MBI-PA score & & $\boldsymbol{p}$-value \\
\hline Study area & \multicolumn{1}{c}{ Compare to } & 0,049 \\
\hline Emergency and ambulance & Laboratory, Radiology Unit and Office & 0,027 \\
\hline Pandemic Policinic and ICU & Emergency and ambulance & 0,000 \\
\hline Pandemic Policinic and ICU & Laboratory, Radiology Unit and Office & 0,023 \\
\hline Pandemic Policinic and ICU & PH, FP, OP and PS* & \\
\hline
\end{tabular}

*PH: Public Health, FP: Family Practise, OP: Other Policlinics, PS: Patient Service,

MBI: Maslach Burnout Inventory

Table 5. Comparison of Beck Anxiety Inventory and Maslach Burnout Inventory scores according to the survey questions 


\begin{tabular}{|c|c|c|c|c|c|c|c|c|c|}
\hline \multirow[t]{2}{*}{ Questions } & & \multirow{2}{*}{$\begin{array}{l}\text { BAl score } \\
\text { Median(min- } \\
\text { max) }\end{array}$} & \multicolumn{3}{|c|}{$\begin{array}{l}\text { MBI score } \\
\text { Median(min-max) }\end{array}$} & \multicolumn{4}{|c|}{$p$ values } \\
\hline & & & $\mathrm{EE}$ & DP & PA & p1 & p2 & p3 & p4 \\
\hline \multirow[t]{2}{*}{ Gender } & Female & $19(0-63)$ & $\begin{array}{l}30 \\
(9- \\
45)\end{array}$ & $\begin{array}{l}11 \\
(5- \\
25)\end{array}$ & $\begin{array}{l}27 \\
(8- \\
40)\end{array}$ & 0.000 & 0.000 & 0,311 & 0,192 \\
\hline & Male & $10(0-59)$ & $\begin{array}{l}24 \\
(9- \\
45)\end{array}$ & $\begin{array}{l}11 \\
(5- \\
25)\end{array}$ & $\begin{array}{l}26 \\
(8- \\
40)\end{array}$ & & & & \\
\hline \multirow[t]{2}{*}{ Marital status } & Single & $15(0-63)$ & $\begin{array}{l}29 \\
(9- \\
45)\end{array}$ & $\begin{array}{l}11 \\
(5- \\
25)\end{array}$ & $\begin{array}{l}27 \\
(9- \\
40)\end{array}$ & 0,263 & 0,03 & 0,069 & 0,545 \\
\hline & Married & $14(0-59)$ & $\begin{array}{l}27 \\
(9- \\
45)\end{array}$ & $\begin{array}{l}11 \\
(5- \\
25)\end{array}$ & $\begin{array}{l}27 \\
(8- \\
40)\end{array}$ & & & & \\
\hline \multirow[t]{2}{*}{$\begin{array}{l}\text { Live with over } 65 \\
\text { years old family } \\
\text { member? }\end{array}$} & Yes & $18(0-61)$ & $\begin{array}{l}30 \\
(9- \\
45)\end{array}$ & $\begin{array}{l}11 \\
(5- \\
25)\end{array}$ & $\begin{array}{l}27 \\
(10- \\
39)\end{array}$ & 0.000 & 0,007 & 0,26 & 0,687 \\
\hline & No & $13(0-63)$ & $\begin{array}{l}27 \\
(9- \\
45)\end{array}$ & $\begin{array}{l}11 \\
(5- \\
25)\end{array}$ & $\begin{array}{l}27 \\
(8- \\
40)\end{array}$ & & & & \\
\hline \multirow[t]{2}{*}{ Have child? } & Yes & $14(0-63)$ & $\begin{array}{l}29 \\
(9- \\
45)\end{array}$ & $\begin{array}{l}10 \\
(5- \\
25)\end{array}$ & $\begin{array}{l}27 \\
(8- \\
40)\end{array}$ & 0,097 & 0,005 & 0,003 & 0,444 \\
\hline & No & $15(0-61)$ & $\begin{array}{l}27 \\
(9- \\
45)\end{array}$ & $\begin{array}{l}12 \\
(5- \\
25)\end{array}$ & $\begin{array}{l}26 \\
(9- \\
40)\end{array}$ & & & & \\
\hline \multirow{3}{*}{$\begin{array}{l}\text { Do you think that } \\
\text { current events } \\
\text { about COVID19 } \\
\text { affect your } \\
\text { menthal health? }\end{array}$} & Yes & $17(0-63)$ & $\begin{array}{l}29 \\
(9- \\
45)\end{array}$ & $\begin{array}{l}11 \\
(5- \\
25)\end{array}$ & $\begin{array}{l}27 \\
(8- \\
40)\end{array}$ & 0.000 & 0.000 & 0,04 & 0,323 \\
\hline & No & $4(0-61)$ & $\begin{array}{l}18 \\
(9- \\
45)\end{array}$ & $\begin{array}{l}8 \\
(5- \\
25)\end{array}$ & $\begin{array}{l}27 \\
(8- \\
40)\end{array}$ & & & & \\
\hline & Undecided & $8(0-59)$ & $\begin{array}{l}23 \\
(9- \\
45)\end{array}$ & $\begin{array}{l}9 \\
(5- \\
25)\end{array}$ & $\begin{array}{l}26,5 \\
(9- \\
40)\end{array}$ & & & & \\
\hline \multirow[t]{2}{*}{$\begin{array}{l}\text { Do you provide } \\
\text { care to supected } \\
\text { COVID19 patient? }\end{array}$} & Yes & $12(0-55))$ & $\begin{array}{l}30 \\
(9- \\
45)\end{array}$ & $\begin{array}{l}11 \\
(5- \\
25)\end{array}$ & $\begin{array}{l}27 \\
(8- \\
40)\end{array}$ & 0.000 & 0.000 & 0.000 & 0,02 \\
\hline & No & $16,5(0-63)$ & $\begin{array}{l}26 \\
(9- \\
45)\end{array}$ & $\begin{array}{l}10 \\
(5- \\
25)\end{array}$ & $\begin{array}{l}26 \\
(8- \\
40)\end{array}$ & & & & \\
\hline $\begin{array}{l}\text { Is there enough } \\
\text { PPE and } \\
\text { disinfectant in the }\end{array}$ & Yes & $15,5(0-63)$ & $\begin{array}{l}29 \\
(9- \\
45)\end{array}$ & $\begin{array}{l}10 \\
(5- \\
25)\end{array}$ & $\begin{array}{l}27 \\
(8- \\
40)\end{array}$ & 0.000 & 0.000 & 0,004 & 0,035 \\
\hline
\end{tabular}




\begin{tabular}{|c|c|c|c|c|c|c|c|c|c|}
\hline $\begin{array}{l}\text { hospital / where } \\
\text { you work? }\end{array}$ & No & $12(0-61)$ & $\begin{array}{l}24 \\
(9- \\
45)\end{array}$ & $\begin{array}{l}11 \\
(5- \\
25)\end{array}$ & $\begin{array}{l}26 \\
(8- \\
40)\end{array}$ & & & & \\
\hline \multirow[t]{2}{*}{$\begin{array}{l}\text { Do you believe } \\
\text { that PPE protect } \\
\text { to you? }\end{array}$} & Yes & $16(0-63)$ & $\begin{array}{l}22 \\
(9- \\
45)\end{array}$ & $\begin{array}{l}9 \\
(5- \\
25)\end{array}$ & $\begin{array}{l}27 \\
(8- \\
40)\end{array}$ & 0.000 & 0.000 & 0.000 & 0,271 \\
\hline & No & $10(0-61)$ & $\begin{array}{l}29 \\
(9- \\
45)\end{array}$ & $\begin{array}{l}11 \\
(5- \\
25)\end{array}$ & $\begin{array}{l}26 \\
(8- \\
40)\end{array}$ & & & & \\
\hline \multirow[t]{2}{*}{$\begin{array}{l}\text { Are you afraid of } \\
\text { getting COVID19 } \\
\text { infection? }\end{array}$} & Yes & $16(0-63)$ & $\begin{array}{l}29 \\
(9- \\
45)\end{array}$ & $\begin{array}{l}11 \\
(5- \\
25)\end{array}$ & $\begin{array}{l}27 \\
(8- \\
40)\end{array}$ & 0.000 & 0.000 & 0,327 & 0,44 \\
\hline & No & $7(0-61)$ & $\begin{array}{l}22 \\
(9- \\
45)\end{array}$ & $\begin{array}{l}10 \\
(5- \\
25)\end{array}$ & $\begin{array}{l}27 \\
(9- \\
40)\end{array}$ & & & & \\
\hline
\end{tabular}

Table 6. Spearman Correlation analysis of BAI and MBI scores.

\begin{tabular}{|c|c|c|c|c|c|c|}
\hline & & $\begin{array}{l}\text { Spearman } \\
\text { Correlation }\end{array}$ & $\begin{array}{l}\text { BAl } \\
\text { score }\end{array}$ & & MBI score & \\
\hline & & & & $\begin{array}{l}\text { Emotional } \\
\text { exhaustion }\end{array}$ & Depersonalization & $\begin{array}{l}\text { Personal } \\
\text { accomplishment }\end{array}$ \\
\hline \multirow{2}{*}{$\begin{array}{l}\text { BAI } \\
\text { score }\end{array}$} & & $r$ & 1 & 470 & 240 &,- 162 \\
\hline & & $p$ value & . & 0 & 0 & 0 \\
\hline \multirow[t]{6}{*}{$\begin{array}{l}\text { MBI } \\
\text { score }\end{array}$} & $\begin{array}{l}\text { Emotional } \\
\text { exhaustion }\end{array}$ & $r$ & ,470 & 1 & 693 &,- 306 \\
\hline & & $p$ value & 0 & & 0 & 0 \\
\hline & Depersonalization & $r$ & 240 & ,693 & 1 &,- 335 \\
\hline & & $p$ value & 0 & 0 & . & 0 \\
\hline & $\begin{array}{l}\text { Personal } \\
\text { accomplishment }\end{array}$ & $r$ &,- 162 &,- 306 &,- 335 & 1 \\
\hline & & $P$ value & 0 & 0 & 0 & . \\
\hline
\end{tabular}

BAl: Beck Anxiety Inventory, MBI: Maslach Burnout Inventory

\section{Supplementary Files}

This is a list of supplementary files associated with this preprint. Click to download.

- COVID19AnxietyandBurnoutSurveyForm.pdf 